\title{
Treatment Challenges with Benign Bone Tumors of the Orbit
}

\author{
Helen Merritt ${ }^{a, c}$ Vivian T. Yin ${ }^{a}$ Margaret L. Pfeiffer ${ }^{a, c}$ Wei-Lien Wang ${ }^{b}$ \\ Matthew C. Sniegowski ${ }^{a}$ Bita Esmaeli ${ }^{a}$ \\ a Orbital Oncology and Ophthalmic Plastic Surgery Program, Department of Plastic Surgery, \\ and ${ }^{\mathrm{b}}$ Department of Pathology, The University of Texas MD Anderson Cancer Center, and \\ 'Ruiz Department of Ophthalmology and Visual Science, The University of Texas Health \\ Science Center at Houston, Houston, Tex., USA
}

\section{Key Words}

Mesenchymal tumors · Orbital bones · Facial deformity · Fibro-osseous lesions · Reactive bone lesions · Juvenile ossifying fibroma · Central giant cell granuloma

\begin{abstract}
Benign mesenchymal tumors of the craniofacial complex present unique challenges for orbital surgeons because of their potential for orbital compartment syndrome, ocular morbidity, and facial disfigurement and because definitive surgical management may be associated with significant morbidity. While the precise classification of such lesions depends on radiologic as well as histologic evaluations and remains controversial, benign tumors involving the bony walls of the orbit share features of bony expansion, facial deformity, and the potential to cause significant orbital and ophthalmic morbidity. We herein present 2 cases of benign mesenchymal tumors with bony involvement in the orbitofacial region ( 1 juvenile ossifying fibroma and 1 central giant cell granuloma) and review the current management of similar benign fibro-osseous and reactive bone lesions of the orbit. These rare entities presented share common orbital and ophthalmic manifestations and remain without any effective definitive treatment options.

(C) 2015 S. Karger AG, Basel
\end{abstract}

\section{Introduction}

Benign mesenchymal tumors involving the bony walls of the orbit and craniofacial complex encompass a broad range of pathologies and can be categorized into the broad groups of fibro-osseous lesions, cartilaginous lesions, reactive bone lesions, and vascular 

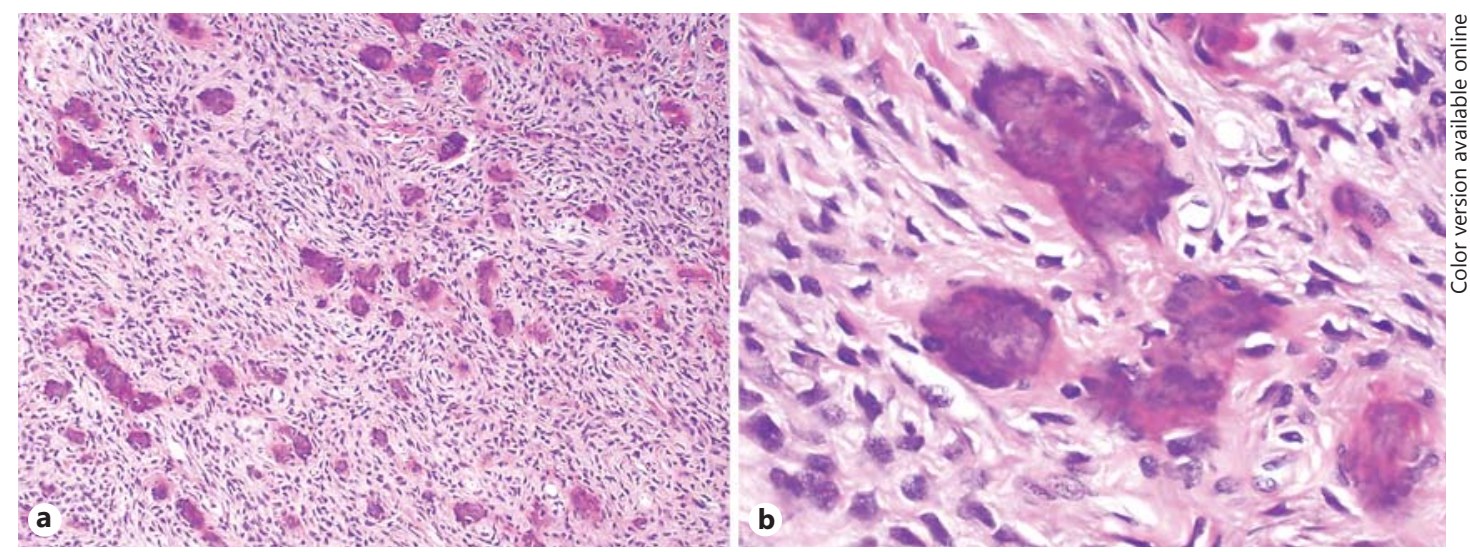

Fig. 1. Histologic findings in juvenile ossifying fibroma. a Cellular tumor with multiple psammomatous calcifications. HE. $\times 100$. b High-power magnification revealing bland, short spindle cells and calcifications. HE. $\times 400$.

lesions [1, 2]. Because of the rarity of these tumors, there is a lack of evidence on the best approach to the management of their orbital and ophthalmic sequelae, most commonly progressive slow or subacute mass effect causing proptosis, ocular displacement, and orbital compartment syndrome [1]. We present 2 cases of benign histologically distinct osseous tumors ( 1 juvenile ossifying fibroma and 1 central giant cell granuloma) with similar presentation to highlight common orbital and ophthalmic manifestations and to underscore the associated treatment challenges. We also review the literature for the reported management options for these described cases as well as other similar fibro-osseous and reactive benign osseous lesions of the orbit. This review was conducted in compliance with HIPAA guidelines.

\section{Case Reports}

Case 1: Juvenile Ossifying Fibroma

A 7-year-old boy was diagnosed with bilateral Wilms' tumor in March 2002 and treated with adjuvant chemotherapy with the combination of vincristine, dactinomycin, and cyclophosphamide followed by ifosfamide and right (October 2002) and left (December 2002) parenchyma-preserving nephrectomy. He also received 18 Gy of adjuvant radiation and chemotherapy with cyclophosphamide $2.4 \mathrm{~g} / \mathrm{m}^{2}$ in March 2003.

In August 2006, after the patient had complained of swelling of the left jaw for 2 weeks, he was found to have an osteolytic lesion involving the left mandible. A biopsy confirmed the diagnosis of juvenile active ossifying fibroma (fig. 1), and the patient was treated with complete surgical resection in January 2007. He was also found to have a left parathyroid adenoma with associated hyperparathyroidism in March 2010 and was treated with surgical resection.

In June 2009, a follow-up computed tomography (CT) showed new osseous lesions involving both maxillae and the right mandible. Despite treatment with calcitonin from August 2010 to December 2010, the lesions progressed clinically, and a CT assessment showed enlargement of the lesions with extension into both orbits and destruction of both nasolacrimal ducts (fig. 2). In January 2011, the disease in the maxillary and ethmoid sinus was surgically debulked through an endoscopic approach. In February 2011, a trial with 3 million units of interferon daily was started. A CT in November 2011 showed minimal but documented progression of the tumor size (left maxillary tumor: $6.2 \mathrm{~cm}$, compared to $5.9 \mathrm{~cm}$ in August 2011 and $5.3 \mathrm{~cm}$ in February 2011). In February 2012, cyclophosphamide was added to try to stabilize the disease. A CT in June 2012 confirmed disease stabilization.

In July and October 2012, the patient received 2 treatments with $1 \mu \mathrm{Ci} / \mathrm{kg}$ samarium-153 lexidronam in the hope that this would decrease the tumor size. Samarium-153 lexidronam, a radioactive isotope coupled with ethylenediamine tetramethylene phosphonic acid, has an affinity for sites of new bone formation and is 
Ocular Oncology

and Pathology

\begin{tabular}{l|l}
\hline Ocul Oncol Pathol 2015;1:111-120 \\
\hline DOI: 10.1159/000368651 & $\begin{array}{l}\text { @ 2015 S. Karger AG, Basel } \\
\text { www.karger.com/oop }\end{array}$ \\
\hline
\end{tabular}

Merritt et al.: Treatment Challenges with Benign Bone Tumors of the Orbit
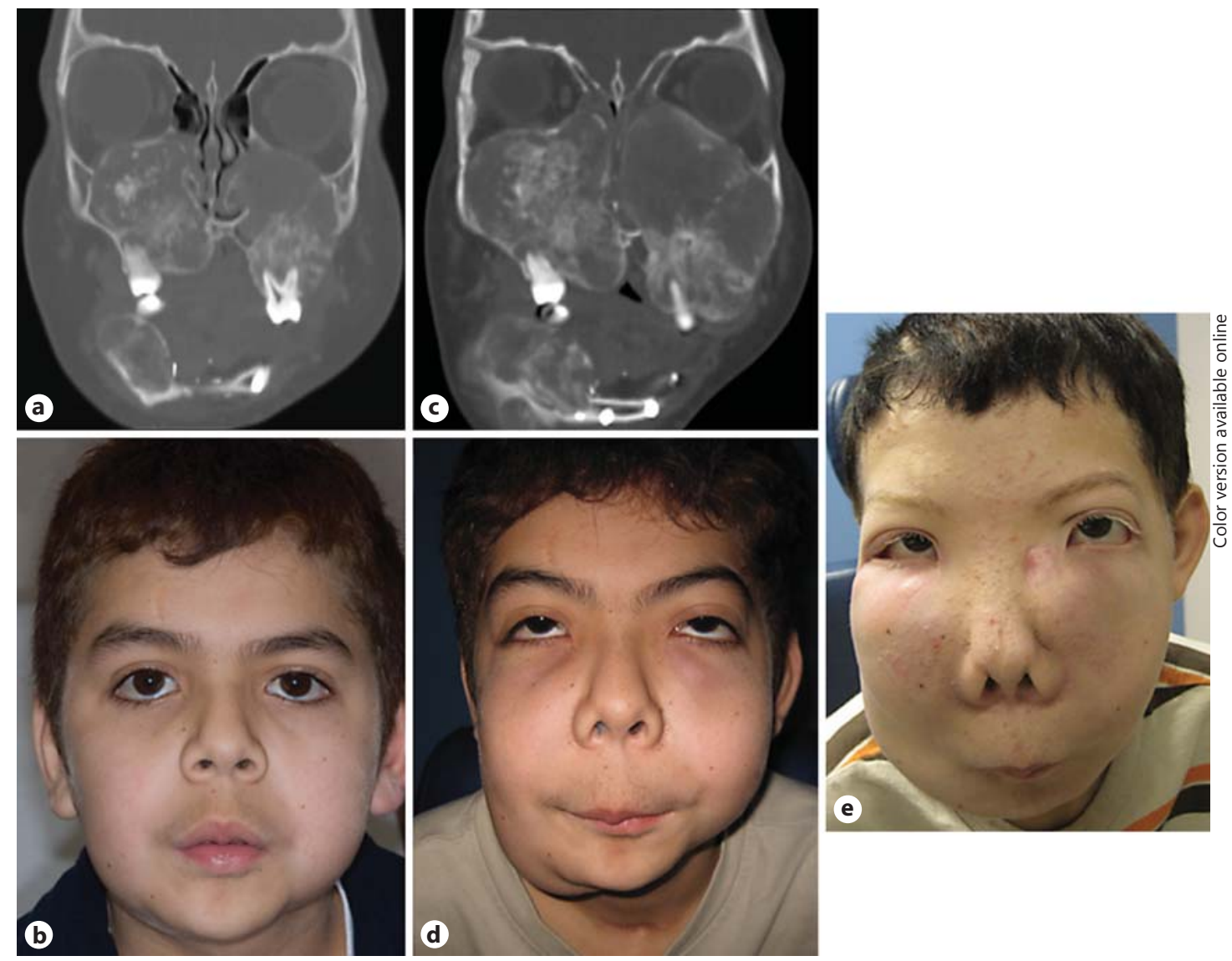

Fig. 2. Clinical findings in our patient with juvenile ossifying fibroma. a Coronal CT scan with contrast showing bilateral maxillary and right mandibular bone lesions. Both the right and left infraorbital foramina are displaced by the bilateral maxillary tumor, and the floor of the right orbit is partly eroded. The tumor also extends into both the nasal cavity and apices of multiple teeth. $\mathbf{b}$ Clinical photograph showing distortion of the right mandibular angle from the tumor and subtle maxillary mass. c Repeat coronal CT scan with contrast in December 2010 showing progression of the tumor of the bilateral maxillary bone and right mandibular bone. There is more extensive involvement of the nasal cavity and sphenoid and ethmoid sinus obstruction. The tumor of the left maxilla now displaces the medial rectus muscle and obstructs the nasolacrimal duct. There was no orbital apical involvement on either side. $\mathbf{d}$ Corresponding clinical photograph in December 2010 showing a significant increase in tumor size with prominent bilateral maxillary and right mandibular masses. The maxillary tumors are causing mechanical downward slanting of both lateral canthal angles and increased inferior scleral show. e Clinical photograph at the last follow-up in December 2013 showing stabilization of tumor growth. Significant facial bone distortion is noted, resulting in distortion of the lateral canthal angle and normal lid position as well as loss of the nasal bridge and jaw contour.

approved by the US Food and Drug Administration for the treatment of painful osteoblastic metastases. Unfortunately, despite treatment with this drug, the tumor size increased by January 2013.

In February 2013, the patient was started on pazopanib, a multi-tyrosine kinase inhibitor of the vascular endothelial growth factor receptor and platelet-derived growth factor receptor. At the last follow-up in December 2013, the patient's tumors had not increased in size.

\section{Case 2: Central Giant Cell Granuloma}

A 27-year-old woman presented in March 2010 with positional reading difficulty and difficulty opening her right eye since late 2009. She was found to have bilateral maxillary bone masses, and resection and pathologic evaluation of the right maxillary mass in March 2010 showed a giant cell granuloma. The patient had 
Ocular Oncology

and Pathology

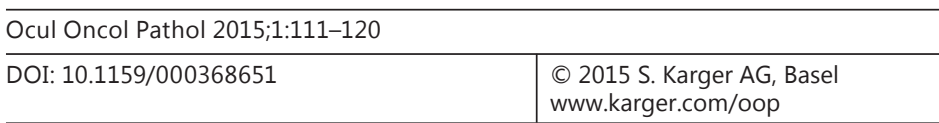

Merritt et al.: Treatment Challenges with Benign Bone Tumors of the Orbit
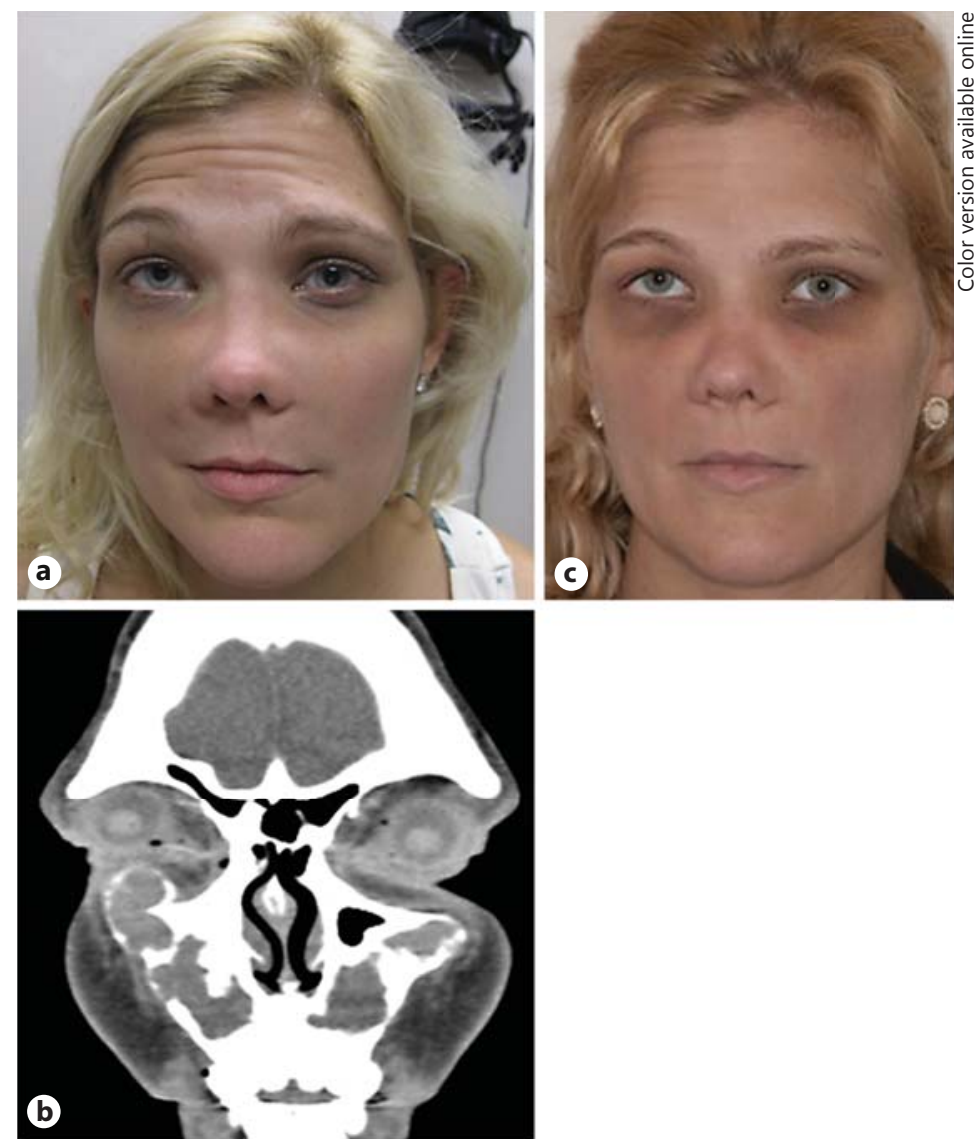

Fig. 3. Clinical findings in our patient with central giant cell granuloma. a Clinical photograph at presentation showing bilateral maxillary bone prominence and right hyperglobus. b Coronal CT scan with contrast showing bilateral expansile fibro-osseous processes of both anterior maxillae. There is extension along the floor and extension into the right orbit with displacement of the right globe. c Clinical photograph at the last follow-up showing stabilization of and a possibly slight decrease in the maxillary mass.

previously undergone evaluations for the possibility of neurofibromatosis type 1 because of the presence of café au lait spots, cystic lesions of the mandible, and facial asymmetry with prominent right zygoma in 1995; the results of those evaluations were inconclusive.

The patient presented to our institution for management in October 2012 with right hyperglobus, supraduction limitation of the right eye, and facial pain. Imaging revealed extensive bilateral maxillary fibro-osseous lesions with extension into the inferior right orbit (fig. 3). A repeat biopsy of the right maxilla confirmed the diagnosis of giant cell reparative granuloma of the bone (central giant cell granuloma) with patchy RANK ligand staining (fig. 4). Since January 2013, the patient has been treated with interferon at a dose of $1.1 \mu \mathrm{g} / \mathrm{kg}$ weekly and denosumab at a dose of $120 \mathrm{mg}$ (Xgeva) monthly, which has resulted in a stable size of the lesions and a decrease in edema despite persistent pain and facial deformity at the last follow-up in January 2014.

\section{Discussion}

We present 2 cases of benign intra-osseous lesions involving the craniofacial bones causing significant orbital signs, facial deformity, and pain despite being histopathologically benign. These cases exemplify the difficulty of managing these 'benign' tumors as there are often no standard established treatment options that have proven uniformly effective. They also demonstrate the degree of orbitofacial disfigurement and morbidity that can be potentially caused by these nonmalignant lesions. These cases exemplify two broad categories of benign primary orbital bone tumors: benign fibro-osseous lesions and reactive bone lesions, as categorized by Selva et al. [1]. Juvenile ossifying fibroma accompanies lesions such as fibrous dysplasia and osteomas in the category of benign orbital fibro-osseous lesions. Central 


\section{Ocular Oncology \\ and Pathology}

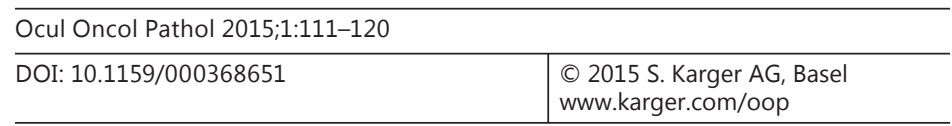

Merritt et al.: Treatment Challenges with Benign Bone Tumors of the Orbit
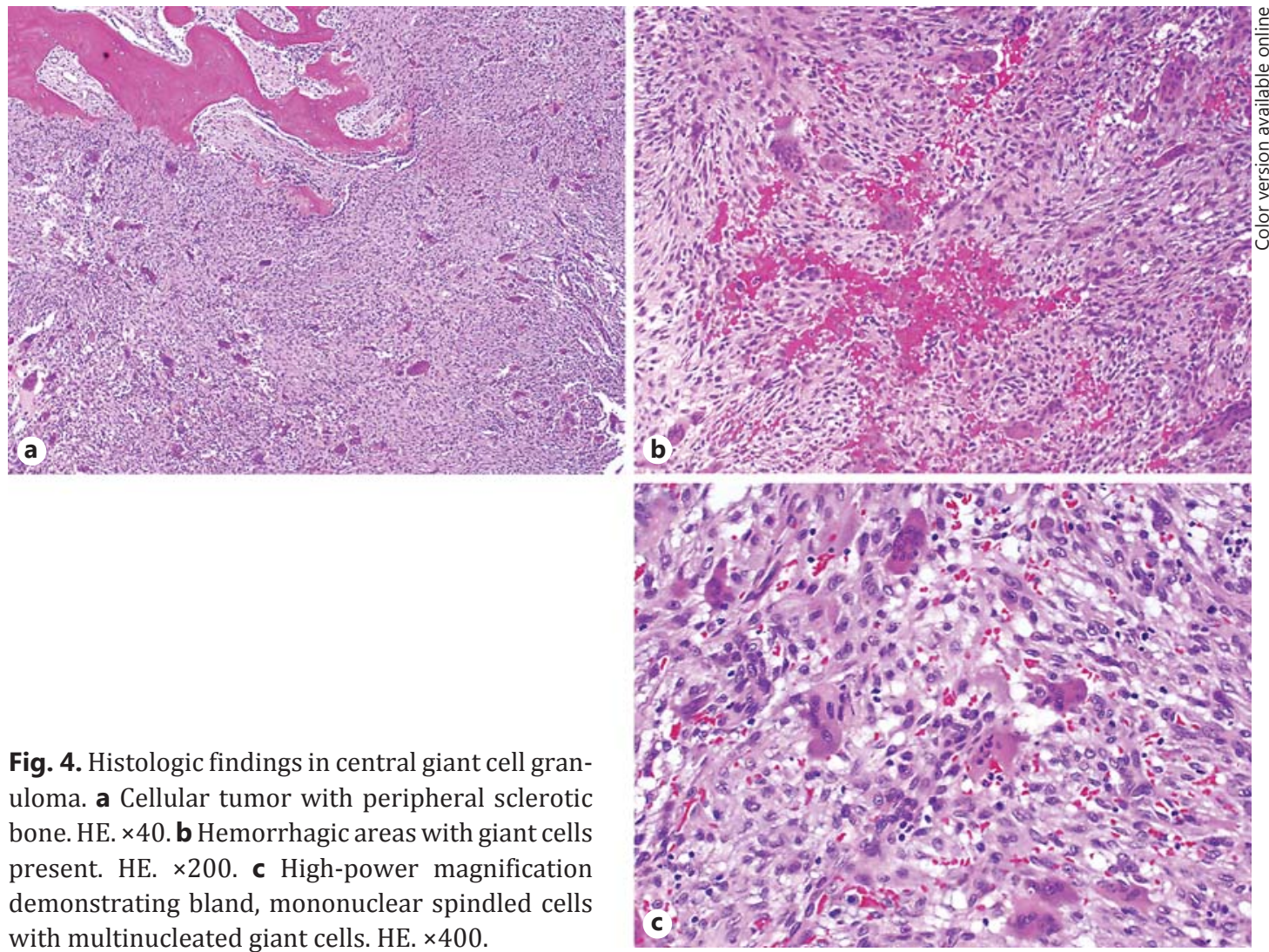

Fig. 4. Histologic findings in central giant cell granuloma. a Cellular tumor with peripheral sclerotic bone. HE. $\times 40$. b Hemorrhagic areas with giant cells present. HE. $\times 200$. c High-power magnification demonstrating bland, mononuclear spindled cells with multinucleated giant cells. HE. $\times 400$.

giant cell granuloma exemplifies the category of other similar reactive bone lesions of the orbit, which also includes aneurysmal bone cysts. In the following paragraphs, we will discuss various treatment options for our reported cases that have been described in the literature as well as review the current management of similar benign bone tumors of the orbit.

\section{Benign Fibro-Osseous Lesions of the Orbit}

Juvenile Ossifying Fibroma

Juvenile ossifying fibroma is a benign fibro-osseous neoplasm involving the craniofacial bones. It is classified into two subtypes: juvenile psammomatoid ossifying fibroma and juvenile trabecular ossifying fibroma [3]. As these lesions can arise near the paranasal sinuses, maxillae, and frontal bone and demonstrate expansile and locally aggressive behavior, they may produce morbidity through localized mass effects [4]. Most commonly, ophthalmic symptoms include proptosis, diplopia, ptosis, and motility restriction $[1,4,5]$. Optic nerve compromise and vision loss are rare but have been described in 3 individual case reports [5-7]. Because juvenile ossifying fibroma is slowly progressive, deformity and symptoms may not be noted until the disease becomes advanced [8]. This disease may also cause acute orbital inflammation and mimic orbital cellulitis [9].

The most common treatment for symptomatic juvenile ossifying fibroma is complete surgical excision, but recurrence rates can be as high as $30 \%$ even after total resection $[5,10]$. Importantly, the chance of cosmetic deformity must be considered, and for small lesions, a more conservative surgical approach may be utilized [11,12]. Such a conservative approach, consisting of curettage, aims to lessen the risks of orbital floor violation and nerve damage. A collaboration with experts in radiology, neurosurgery, otolaryngology, or craniofacial surgery 


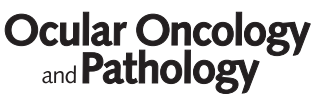

Ocular Oncology
and Pathology

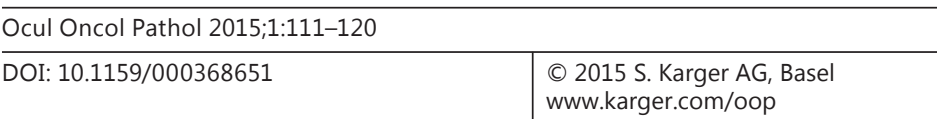

is often necessary for surgical planning and management to ensure an optimal outcome and decrease the chance of recurrence $[8,13]$. As of this writing, no case of malignant transformation of juvenile ossifying fibroma has been reported in the literature.

The use of an adjuvant systemic therapy with interferon alpha has shown promising results in terms of decreasing the local recurrence rate. One case series of 3 patients treated with 6-12 months of adjuvant subcutaneous interferon injection following complete surgical resection showed no recurrences during a mean follow-up period of 35 months [14].

In our patient with juvenile ossifying fibroma, the significant size and the location of the tumors made surgical removal a poor treatment option, as resection would have led to significant further facial disfigurement. We have therefore treated him with trials of several drugs that have been shown to be effective in cancer treatment, including cyclophosphamide, samarium, and pazopanib, in hopes of halting the clinical progression of his disease.

Fibrous Dysplasia

Fibrous dysplasia is also a slowly progressive proliferation of benign fibrous tissue found in association with orbital bones and may be monofocal (monostotic) or multifocal (polyostotic). The orbital roof is the most commonly affected wall of the orbit as the sphenoid, frontal, and ethmoid bones are often involved [15]. Characteristic histopathologic findings include trabeculae of woven bone, often said to resemble Chinese letters, mixed with fibrous tissue. Radical resection of the affected craniofacial bones is the treatment of choice followed by immediate complex craniofacial reconstruction, as partial resection has been associated with disease recurrence [16-18].

Controversy exists regarding the appropriate management of tumors involving the orbital apex: some advocate for prophylactic decompression of the optic canal $[19,20]$, while others believe that optic canal involvement does not typically cause a compressive optic neuropathy [21]. Vision loss is often attributed to tumor-associated cysts, hemorrhage, or mucoceles rather than the tumor itself, arguing for more effective surgical management by general debulking rather than optic canal decompression [21]. Furthermore, in 19 orbits with radiographic evidence of a narrowing of the optic canal and superior orbital fissure, no patient exhibited signs of visual loss or hypoesthesia indicative of compromise of cranial nerves 2 or 5 [15].

Few efficacious nonsurgical treatment options exist. Malignant transformation is possible, and radiation therapy increases the risk of malignant degeneration [22, 23]. Treatment with bisphosphonates has produced inconsistent results [24]. For example, in a randomized controlled trial of 40 patients treated with alendronate, there was a significant reduction in one marker of bone turnover (NTX-telopeptide), but no significant effect on another marker (serum calcitonin) or on associated pain could be observed [25]. Recently, denosumab, a monoclonal antibody targeting RANK ligand, has shown promise in reducing tumor growth rate and pain $[26,27]$.

\section{Osteoma}

Osteomas are benign, slow-growing bone proliferations that, when located in the head and neck region, often arise from the paranasal sinuses. The location is most commonly the frontal and ethmoid sinuses, and these lesions may rarely secondarily invade the orbit [28, 29]. Histologically, osteomas are small, well-circumscribed lesions that consist of variable amounts of cancellous (mature) and compact (ivory) bone. A subtype of osteoma with osteoblastoma-like features described by McHugh et al. [28] contains areas of woven bone trabeculae surrounded by osteoblasts, osteoclasts, and fibrovascular stroma and has higher association with larger size and visual changes. 
Merritt et al.: Treatment Challenges with Benign Bone Tumors of the Orbit

Incidental discovery of osteomas on imaging is common, and treatment is not necessary if asymptomatic [30]. When indicated due to manifest symptoms related to mass effect, treatment consists of total or subtotal surgical resection. External surgical approaches include coronal, transcaruncular, tranconjunctival, and transblepharoplasty incision. Endoscopic or combined external/endoscopic approaches are also well described and may require a multidisciplinary surgical team $[29,31]$. To our knowledge, medical therapies do not exist.

\section{Benign Reactive Bone Lesions of the Orbit}

Central Giant Cell Granuloma

Central giant cell granuloma, also known as giant cell reparative granuloma, is a benign intraosseous lesion comprised of cellular fibrotic tissue. Pathologic examination shows foci of hemorrhage, aggregations of multinucleated giant cells, and woven bone trabeculae [32]. Central giant cell granulomas are most commonly found in the jaw, with location in the mandible twice as common as location in the maxilla, but may also involve the temporal bone, frontal bone, or orbit $[33,34]$. Patients typically present with painless, progressive swelling of the face [35]. Central giant cell granuloma of the maxilla is generally located anteriorly and has a higher likelihood of expansion causing cortical thinning and destruction [36]. It can be differentiated into two categories, aggressive and nonaggressive, on the basis of symptoms, radiographic findings, and number of giant cells on histopathologic study [36]. Aggressive lesions are more likely to present with faster growth and destruction of adjacent structures, have a greater tendency to recur, and have increased vascular density, which makes them more responsive to antiangiogenic therapy [37].

Although authors of early descriptions of central giant cell granuloma hypothesized that the lesion was related to a reactive, reparative response to trauma or hemorrhage, most cases do not correspond to a previous injury or history of inflammation. The advocated treatment is surgical excision with curettage; however, recurrence has been reported in 4-37\% of cases [34-36, 38]. In 1 case series, radical en bloc resection with wide local excision and with margins of $1 \mathrm{~cm}$ was employed in 18 locally aggressive cases characterized by large size, high growth rate, and severe pain, and there was only $1(6 \%)$ recurrence during a mean follow-up time of 3.9 years [39]. Although local control is increased with wide resection, this approach may be overly aggressive for a benign lesion and lead to higher morbidity and facial deformity at the resection site.

Some investigators have suggested a decreased risk of recurrence with the use of adjuvant radiotherapy $[33,40]$. In a series of 4 patients with large or recurrent lesions treated with adjuvant radiotherapy of 9.6-60 Gy after surgical excision, only 1 recurrence was found at a mean follow-up time of 10.75 years [40]. Two cases of malignant transformation to osteosarcoma after radiotherapy have been reported [41].

A meta-analysis of the 17 patients with central giant cell granuloma reported in the literature to have been treated with intralesional injection of triamcinolone weekly or biweekly for 1-60 weeks showed complete resolution of the disease involving the jaw and orbital bones [42]. Response to intralesional triamcinolone has been shown to be associated with younger age and mandible lesion location [42].

Intranasal and subcutaneous therapy with calcitonin, an inhibitor of osteoclastogenesis and proliferation, has been reported to be an effective treatment in several individual case series. However, a randomized double-blind controlled trial by de Lange et al. [43] of 14 patients with central giant cell granuloma of the jaw found no significant difference in the proportion of patients with tumor size reduction $\geq 10 \%$ between patients treated with intranasal calcitonin and those treated with placebo at time points of 15 months of treatment and 6 months after the end of treatment. 


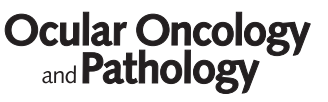

Ocular Oncology
and Pathology

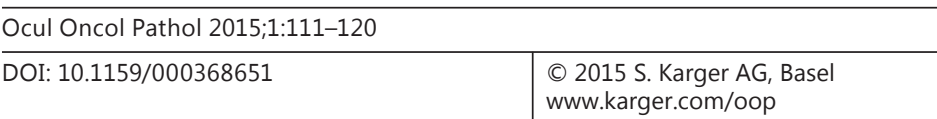

Merritt et al.: Treatment Challenges with Benign Bone Tumors of the Orbit

Vered et al. [44] found a significant and variable presence of glucocorticoid and calcitonin receptors in 41 pathologic specimens of central giant cell granuloma and hypothesized that this disease represents a heterogeneous group of proliferations that respond differently to treatments according to the individual expression of these target receptors. This suggests that immunohistochemical study of each lesion may determine the most effective individualized treatment.

Recently, adjuvant therapy with interferon alpha-2a or alpha- $2 \mathrm{~b}$ at 3 million units $/ \mathrm{m}^{2}$ subcutaneously once daily for 6-8 months after conservative surgical excision has shown successful prevention of recurrence in aggressive lesions of the mandible [45-47]. Two small series of 2 and 7 patients treated with tumor excision followed by subcutaneous interferon demonstrated no tumor recurrences over time periods ranging from 2 to 12 years after surgery $[45,46]$. A larger series of 26 patients treated similarly with interferon for an average duration of 8 months after conservative surgical excision showed no recurrences at 2 years [47]. These studies suggest that adjuvant therapy with interferon alpha-2a or $-2 b$ may result in lower rates of recurrence while sparing patients the morbidity of large en bloc resection.

Aneurysmal Bone Cyst

An aneurysmal bone cyst is a benign vascular lesion consisting of intraosseous vascular channels that expand and destroy cortical bone. It typically involves the long bones but may rarely arise in the orbit, most commonly in the orbital roof [48]. Typically, these lesions have a period of slow growth of several months (average of 14 weeks) followed by a period of rapid growth and deterioration, prompting many patients to seek treatment [48]. Histologically, it consists of cysts filled with red blood cells surrounded by a fibrous connective tissue with multinucleated giant cells. Complete surgical excision is the treatment of choice, which may include curettage, cryotherapy, resection, arterial embolization, and bone grafting. Excision and curettage definitively treated $90 \%$ of lesions in one series of 120 maxillofacial aneurysmal bone cysts [49]. The authors reported an approximately $10 \%$ recurrence rate after complete excision [49]. Adjuvant radiation has been associated with malignant transformation and is therefore not recommended; however, cases have progressed to malignancy without prior radiation [50]. Sclerotherapy is an alternative with relative success for aneurysmal bone cysts not amenable to surgical treatment, although we cannot find a case of sclerotherapy for an orbital lesion [51, 52]. Recently, Pelle et al. [53] have demonstrated strong RANK ligand expression in stromal cells in vivo and tumor shrinkage in a 5-year-old boy with a large sacral aneurysmal bone cyst treated with denosumab [54].

\section{Conclusion}

Our 2 presented cases demonstrate the significant degree of orbitofacial symptoms and deformity caused by benign osseous lesions in the periorbital region. These cases and the subsequent discussion of other similar benign orbital fibro-osseous and reactive bone lesions highlight the limited treatment options for advanced cases. While total surgical resection is often the definitive treatment recommended for each lesion, such intervention in our patients would have required the removal and replacement of the entire midface. Other treatments such as chemotherapy, interferons, and targeted therapies with the RANK ligand inhibitors show promise in several of these lesions but warrant further study. Future efforts should focus on the identification of molecular signatures of these tumors and the discovery of potential targets for nonsurgical treatment of each individual lesion. 
Ocular Oncology

and Pathology
Ocul Oncol Pathol 2015;1:111-120

DOI: $10.1159 / 000368651$

Merritt et al.: Treatment Challenges with Benign Bone Tumors of the Orbit

\section{Acknowledgment}

Supported by the NIH/NCI under award number P30CA016672.

\section{Disclosure Statement}

The authors have no conflict of interest to declare.

\section{References}

1 Selva D, White VA, O'Connell JX, Rootman J: Primary bone tumors of the orbit. Surv Ophthalmol 2004;49: 328-342.

-2 Eversole R, Su L, ElMofty S: Benign fibro-osseous lesions of the craniofacial complex. A review. Head Neck Pathol 2008;2:177-202.

-3 El-Mofty S: Psammomatoid and trabecular juvenile ossifying fibroma of the craniofacial skeleton: two distinct clinicopathologic entities. Oral Surg Oral Med Oral Pathol Oral Radiol Endod 2002;93:296-304.

-4 Margo CE, Ragsdale BD, Perman KI, Zimmerman LE, Sweet DE: Psammomatoid (juvenile) ossifying fibroma of the orbit. Ophthalmology 1985;92:150-159.

-5 Johnson LC, Yousefi M, Vinh TN, Heffner DK, Hyams VJ, Hartman KS: Juvenile active ossifying fibroma. Its nature, dynamics and origin. Acta Otolaryngol Suppl 1991;488:1-40.

6 Margo CE, Weiss A, Habal MB: Psammomatoid ossifying fibroma. Arch Ophthalmol 1986;104:1347-1351.

-7 Hasturk A, Tun K, Guvenc Y, Kaptanoglu E: Cranial ossifying fibroma causing visual disorder. J Craniofac Surg 2010;21:768-770.

-8 Hartstein ME, Grove AS Jr, Woog JJ, Shore JW, Joseph MP: The multidisciplinary management of psammomatoid ossifying fibroma of the orbit. Ophthalmology 1998;105:591-595.

-9 Cruz AA, Alencar VM, Figueiredo AR, de Paula S, Eichenberger GC, Chahud F, et al: Ossifying fibroma: a rare cause of orbital inflammation. Ophthal Plast Reconstr Surg 2008;24:107-112.

10 Eversole LR, Leider AS, Nelson K: Ossifying fibroma: a clinicopathologic study of sixty-four cases. Oral Surg Oral Med Oral Pathol 1985;60:505-511.

-11 Hakeem AH, Hakeem IH: Intraoral sublabial approach for anterior skull base juvenile ossifying fibroma. J Craniofac Surg 2011;22:1976-1977.

12 Slootweg PJ, Müller H: Juvenile ossifying fibroma. Report of four cases. J Craniomaxillofac Surg 1990;18:125129.

13 Blitzer A, Post KD, Conley J: Craniofacial resection of ossifying fibromas and osteomas of the sinuses. Arch Otolaryngol Head Neck Surg 1989;115:1112-1115.

14 Kelly PR: Poster 014:Interferon alpha therapy for aggressive juvenile ossifying fibroma. J Oral Maxillofac Surg 2008;66(suppl 8):76-77.

-15 Cruz AA, Constanzi M, de Castro FA, dos Santos AC: Apical involvement with fibrous dysplasia: implications for vision. Ophthal Plast Reconstr Surg 2007;23:450-454.

-16 Moore AT, Buncic JR, Munro IR: Fibrous dysplasia of the orbit in childhood. Clinical features and management. Ophthalmology 1985;92:12-20.

17 Munro IR, Chen YR: Radical treatment for fronto-orbital fibrous dysplasia: the chain-link fence. Plast Reconstr Surg 1981;67:719-730.

18 Goisis M, Biglioli F, Guareschi M, Frigerio A, Mortini P: Fibrous dysplasia of the orbital region: current clinical perspectives in ophthalmology and cranio-maxillofacial surgery. Ophthal Plast Reconstr Surg 2006;22:383387.

19 Chen YR, Breidahl A, Chang CN: Optic nerve decompression in fibrous dysplasia: indications, efficacy, and safety. Plast Reconstr Surg 1997;99:22-30; discussion 31-33.

-20 Papay FA, Morales L Jr, Flaharty P, Smith SJ, Anderson R, WAlker JM, et al: Optic nerve decompression in cranial base fibrous dysplasia. J Craniofac Surg 1995;6:5-10; discussion 11-14.

-21 Michael CB, Lee AG, Patrinely JR, Stal S, Blacklock JB: Visual loss associated with fibrous dysplasia of the anterior skull base. Case report and review of the literature. J Neurosurg 2000;92:350-354.

22 Ruggieri P, Sim FH, Bond JR, Unni KK: Malignancies in fibrous dysplasia. Cancer 1994;73:1411-1424.

23 Yabut SM Jr, Kenan S, Sissons HA, Lewis MM: Malignant transformation of fibrous dysplasia. A case report and review of the literature. Clin Orthop Relat Res 1988;228:281-289.

-24 Lee JS, FitzGibbon EJ, Chen YR, Kim HJ, Lustig LR, Akintoye SO, et al: Clinical guidelines for the management of craniofacial fibrous dysplasia. Orphanet J Rare Dis 2012;7(suppl 1):S2.

-25 Boyce AM, Kelly MH, Brillante BA, Kushner H, Wientroub S, Riminucci M, et al: A randomized, double blind, placebo-controlled trial of alendronate treatment for fibrous dysplasia of bone. J Clin Endocrinol Metab 2014, Epub ahead of print.

26 Ganda K, Seibel MJ: Rapid biochemical response to denosumab in fibrous dysplasia of bone: report of two cases. Osteoporos Int 2014;25:777-782. 
Merritt et al.: Treatment Challenges with Benign Bone Tumors of the Orbit

$$
\begin{aligned}
& \text { Barnes L, Eveson J, Reichart P, Sidransky D (eds): World Health Organization Classificatio } \\
& \text { Geneva, World Health Organization, 2005, pp 283-328. } \\
& \text { D’Ambrosio AL, Williams SC, Lignelli A, Salchow DJ, Spicer G, Libien J, et al: Clinicopathological } \\
& \text { cell reparative granuloma of the orbit. Neurosurgery 2005;57:773-778; discussion 773-778. }
\end{aligned}
$$
Motamedi MH, Eshghyar N, Jafari SM, Lassemi E, Navi F, Abbas FM, et al: Peripheral and central giant cell granulomas of the jaws: a demographic study. Oral Surg Oral Med Oral Pathol Oral Radiol Endod 2007; 103:e39-e43.

35 de Lange J, van den Akker HP, van den Berg H: Central giant cell granuloma of the jaw: a review of the literature with emphasis on therapy options. Oral Surg Oral Med Oral Pathol Oral Radiol Endod 2007;104:603-615.

-36 Rawashdeh MA, Bataineh AB, Al-Khateeb T: Long-term clinical and radiological outcomes of surgical management of central giant cell granuloma of the maxilla. Int J Oral Maxillofac Surg 2006;35:60-66.

37 Dewsnup NC, Susarla SM, Abulikemu M, Faquin WC, Kaban LB, August M: Immunohistochemical evaluation of giant cell tumors of the jaws using CD34 density analysis. J Oral Maxillofac Surg 2008;66:928-933.

-38 De Lange J, Van den Akker HP: Clinical and radiological features of central giant-cell lesions of the jaw. Oral Surg Oral Med Oral Pathol Oral Radiol Endod 2005;99:464-470.

-39 Bataineh AB, Al-Khateeb T, Rawashdeh MA: The surgical treatment of central giant cell granuloma of the mandible. J Oral Maxillofac Surg 2002;60:756-761.

40 Chuong R, Kaban LB, Kozakewich H, Perez-Atayde A: Central giant cell lesions of the jaws: a clinicopathologic study. J Oral Maxillofac Surg 1986;44:708-713.

-41 Austin LT Jr, Dahlin DC, Royer RQ: Giant-cell reparative granuloma and related conditions affecting the jawbones. Oral Surg Oral Med Oral Pathol 1959;12:1285-1295.

42 Yanik S, Aras MH: Management of central giant cell granuloma of mandible using intralesional corticosteroids: case report and review of literature. J Oral Maxillofac Surg 2013;71:721-722.

43 de Lange J, van den Akker HP, Veldhuijzen van Zanten GO, Engelshove HA, van den Berg H, Klip H: Calcitonin therapy in central giant cell granuloma of the jaw: a randomized double-blind placebo-controlled study. Int J Oral Maxillofac Surg 2006;35:791-795.

44 Vered M, Buchner A, Dayan D: Immunohistochemical expression of glucocorticoid and calcitonin receptors as a tool for selecting therapeutic approach in central giant cell granuloma of the jawbones. Int J Oral Maxillofac Surg 2006;35:756-760.

45 O'Connell JE, Kearns GJ: Aggressive giant cell granuloma of the jaws treated with interferon alpha: a report of two cases. Ir J Med Sci 2013;182:163-170.

46 Kaban LB, Troulis MJ, Ebb D, August M, Hornicek FJ, Dodson TB: Antiangiogenic therapy with interferon alpha for giant cell lesions of the jaws. J Oral Maxillofac Surg 2002;60:1103-1111; discussion 1111-1113.

47 Kaban LB, Troulis MJ, Wilkinson MS, Ebb D, Dodson TB: Adjuvant antiangiogenic therapy for giant cell tumors of the jaws. J Oral Maxillofac Surg 2007;65:2018-2024; discussion 2024.

$\checkmark 48$ Yu JW, Kim KU, Kim SJ, Choi S: Aneurysmal bone cyst of the orbit: a case report with literature review. J Korean Neurosurg Soc 2012;51:113-116.

49 Motamedi MH, Behroozian A, Azizi T, Nazhvani AD, Motahary P, Lotfi A: Assessment of 120 maxillofacial aneurysmal bone cysts: a nationwide quest to understand this enigma. J Oral Maxillofac Surg 2014;72:1523-1530.

50 Brindley GW, Greene JF Jr, Frankel LS: Case reports: malignant transformation of aneurysmal bone cysts. Clin Orthop Relat Res 2005;438:282-287.

51 Brosjö O, Pechon P, Hesla A, Tsagozis P, Bauer H: Sclerotherapy with polidocanol for treatment of aneurysmal bone cysts. Acta Orthop 2013;84:502-505.

52 Dubois J, Chigot V, Grimard G, Isler M, Garel L: Sclerotherapy in aneurysmal bone cysts in children: a review of 17 cases. Pediatr Radiol 2003;33:365-372.

53 Pelle DW, Ringler JW, Peacock JD, Kampfschulte K, Scholten DJ 2nd, Davis MM, et al: Targeting receptor-activator of nuclear kappaB ligand in aneurysmal bone cysts: verification of target and therapeutic response. Transl Res 2014;164:139-148.

54 Lange T, Stehling C, Fröhlich B, Klingenhöfer M, Kunkel P, Schneppenheim R, et al: Denosumab: a potential new and innovative treatment option for aneurysmal bone cysts. Eur Spine J 2013;22:1417-1422. 